\title{
Who Writes and Who Translates: Dalit Epistemology in Writing and Rewriting
}

\author{
Prameela K P
}

Concept of original and need of faithfulness or equivalence are questionable in the case of subaltern (Dalit text translations in Indian context), while it is seen that parallel texture and content rewriting are claimed by their translators and editors. Indigenous language and its texture are said to be interwoven with the native life, but it also compromises advancement with time and place, oral traditions and formal or informal literacy imbibed in their jargon and creoles. Equal sensibility, empathy like words are concurrently used in academic discussions to evaluate their translation. Anyhow exotic strategies applied to any other texttranslation are applicable here also. If a writer herself does both the original and translation, these linguistic and textual constraints can be said to be negotiated, but never sensitized. Normally, the practice accepted is to convince the first author and then the process is undertaken on a mutual consent. Instead of the practice of searching for equivalents and prepare paratexts, translation can only be an act of undermining the narratives of Dalit, as this raised by people concerned. Adaptation techniques are only forwarded, which cannot be considered as negative at contexts. Similarly the confusions and lack of coherence realized by Dalits are also points to be looked into. The duality of outsider-insider still persists in academic discussions, whereas the political divide enlarged over the time and again which posit isolation tactics under the same scanner. Representational tactics practiced by political and administrative sectors also add fuel to the discriminative forces. Politically motivated inclusion strategies give way to the cultural and representational divide and keep indirect exclusion within the whole act of implementation. Without unfolding this caste based or representational identity, no step of official implementation is happening around. More clearly, it is agreements and mutual adjustments which render a feeling of representation, but enlarge the divide or exclusion in new but more appropriate ways. Now this paper will be looking into the same practice, interwoven in writing and rewriting.

Keywords: Dalit epistemology, powerful language, mirror images, heterogeneous culture, otherness. 


\section{Introduction}

'The Dalit has a mother tongue. But he cannot talk to the larger society in it-there is no space for his language there. So he has to use written Malayalam, Dalits are people who were denied that freedom of movement by day. So they spoke in a different language. Panan, Parayan, Mannan-all of them have their own language, we have not been able to bring any of that into poetry. Not just poetry-the possibilities embedded in those languages have not been explored those languages have not been explored by Malayalam, There is a whole continent of lost words there'.Raghavan Atholi (Pampirikkunu, 2011: 343)

'Another fundamental difference that Dalit epistemology has with the Brahminic one relates to the way in which knowledge is conceived. Dalit arts view knowledge as the product of material history. In Dalit life, what happens is not the accumulation of knowledge and its expansion in an abstract manner: rather, something oriented to life-praxis and material reproduction. It is concrete as opposed to the Brahminic knowledge system which concerns the abstract'.-Dasan M. (2011: XXViii)

'I look at translation as a cultural weapon......Translation has given me a name and international recognition. My books are now included on university syllabi. Academics read and do research on my books. Translation has contributed to disseminating my thinking processes. I'm not a single-language author anymore. I had never anticipated I could one day be speaking at Universities outside India. I am really delighted and proud of my readers, students, teachers, researchers and my great translators. This is the strength of translation'.- Sharankumar Limbale (Mukherjee, Alok:1)

For a regional language writer, translation of her/his work into English is about to cross the linguistic barriers, an adjunct to procure international recognition and this statement is always felt on the enrichment of the weaker side but to the other hand it also be sensed like politically poised but incorrect. A low strata untouchable, semi-literate person cannot think about wider audience for his literary work in a multilingual Indian background. S/he always needs to express her alien and drastic experiences, poverty stricken melancholies into English so that the power of that language will be perpetuated into her knowledge. Kallen Pokkutan, OmprakashValmiki, Sharankumar Limbale, Bama, Urmila Pawar all these are in same view, with related to their English translations. They feel that circulation and reception of their writings can be enriched and widened through the so called world language translations, which will make them more visible and sustainable in the larger literary domain. Question is that can we follow the canonical, hierarchal mode of rewriting strategies for sharing their experiences and knowledge systems. There is an irony in the textual and political 252 
appropriation of linguistic re-writing of these texts that the regional oral traditions of Tribal/Adivasi expressions never match with the hegemonic ideology and superior nature of English language, or any formally systemized form of literary text. Can we figure out translation as a discovery or a recovery in these transpositions? Is there any imitation or mimicry happening in Indian linguistic translations translated into English as Homi Bhabha, the post-colonial critic has pointed out? Is there any third space formed in the context of third world translations into English including text-transformations of Dalits. Hopes and scopes for international recognition and transnational identity drive all writers including translators to make their versions in English. Counter narratives placed to question the 'othering' phenomenon caused by the use of mainstream poetics in these translations deliberated by leading people and third world sympathizers who stand for a separate Dalit epistemology could make only marginal discussions on them.

\section{Issues in Egalitarian Ethos}

For some people, the issue of caste identity is an integral and unavoidable part of any academic discussion related to Indian society and the social structure. It is also bounded in the study of culture and historiography of the land. Constitutional and administrative arrangements uploaded to covet the racial discrimination during the time and along on the basis of this reality. Postmodern and post structural critiques genuinely highlighted 'the other' in all their discourses. Meanwhile, varieties of expressions and exaggerations have been coming out, got published and widely translated. There is a huge demand for the marginalized voices in the form of print. In some cases, oral expressions have been scripted and transcribed into written languages and have received critical acclaim, where in other cases, someone with a different identity gave linguistic or literal help to the concerned to make her experience literally versioned. In Malayalam, personal and biographical renderings extended by C. K. Janu and Nalini Jameela were widely spread and their translations were also made different marks in respective languages. The demand and market success of these books have improved and encouraged the production of same mannered writings/rewritings. In the beginning, people were eager to know the life shades of these marginalized representatives, distinctive ethnic life modulations and their survival instinct as a community. Caste oppressions, struggles and different personal and community living experiences are their prime areas rendered within. Their political demand for better life has been altogether projected and slowly elevated through these interventions. Even now, publishing experts and academicians are on the lookout of distinctive voices from underprivileged and rare life experiences. ${ }^{1}$ Authority, authenticity and identity politics more

\footnotetext{
${ }^{1}$ Oxford University Press like publishers largely publish ethnic, regional literary contents. M. Dasan , V Pratibha, Pradeepan Pampirikunnu, C.S. Chandrika (eds.) 2011, The Oxford India Anthology of Malayalam Dalit Writing OUP, New Delhi is an example.
} 
visibly indicted in these representative writings make the whole idea of literature as a battle field of differences of opinion. Different or separate notation for a section of people may be academically convenient, but that drives to pre-stipulate their separation and alienation. Centres of inclusion and exclusion, schools for Dalit-Adivasi studies would rarely solve their problems rather study their peculiarities. There is a defensive approach in academic research while attending their problems. This is continued in translation. The question is whether they succeed to incorporate these separate sections of people or is that imminent to continue with those differences on which they claim to be studied. Raising consciousness can be pertinent, which is indeed an outcome of these academic discourses because they also raise media vigilance and cultural integration. At the same time, egalitarian ethos repeatedly used in media on different cast issues countered by respective activists and they ask to revisit the whole idea of pan Indian Dalit equality.

\section{Sympathy or Empathy}

These writings are meant to raise questions on ahistoricity, exclusion and under-inclusion of the underprivileged section. On the contrary, it is also said that they try to conceptualize historicity and essentialism of these cultures in a separate manner. In this case, translation means to make them more visible, and it indicts their identity, underlines their existence, specifies the importance of their community life, places their culture before a wider world and underlines their contributions to mankind.

No doubt, conventional theories do not help much with regard to the problems of translations involved of these narratives in particular with certain circumstances, even seen forcefully excluded or kept quiet method on this matter and their relations with the wider world. Sympathy or empathy depicted towards these people in the mainstream literary world are also questioned and re-read by the later theoreticians. It is found that hierarchal nature of any privileged language drives these narratives towards the opposite direction and put their intentions diluted by the use of its superior nature, though it is said to be reproduced against these temptations. Authority of English language in Indian setup adds fuel to the fire. Against its intention, means to counter the concept of subjectivity has been got indicted and then discriminatory politics becomes imminently readable in these linguistic acts.

\section{Deceptive Translation}

Knowledge-power inter-relations are well pointed out by Michael Foucault. ${ }^{2}$ Naturally, a writer comes from an underprivileged section is a knowledgepropagator or teacher of its people. They usually insist that Dalits want revolution and transformation, not limited change. So they need a translator

\footnotetext{
${ }^{2}$ Here it is also mentionable that latter feminist scholars exploded that woman is absent in all his discourses. Historically knowledge and power, both were used as misogynistic instruments.
} 
with a vision and mission to work on their concerns, not an academic agent or professional to transfer or fetch equivalence. Contrary to this concept, George Steiner the earlier theoretician in translation studies has ascertained that the whole process of translation is deceptive in terms of a powerful language, because it is found that powerful language always benefitted through the act. ${ }^{3}$

Writing can be self liberating experience for many. Over the years, Dalit competence and consciousness has widened in terms of their writings, experiments and innovations tried and executed. Sharpened, pluralistic, multiple forms of their expressions converged with other linguistic and cultural components from time to time. In this point of view, translation of Dalit expressions can be deliberated under the post discourses on 'can the subaltern speak'. ${ }^{4}$ Speaking on behalf or going after experiences might have confronted with new but called parallel connotations. They all have been discussed under the process of subaltern communication. Anybody who is not a representative of a particular community would be considered as a spokes person or an outsider accordingly. These discourses have been often defused, distorted, even derailed by those theoreticians who have been called themselves as insiders. Sometimes they put forward their points well in, on the basis of various life examples. Anyhow political campaign against race, color and caste discriminations become vital in all academic interventions. Thus, identity of the translator is also become a point to mention while discussing about a particular text, as well as the selection of that text.

Social stigma towards castes and racial disgrace towards a person's on the basis of his identity are the issues which collide with the aesthetic and poetic categories of the written or the translated texts. This can happen unknowingly. During the work, Narayan's translator (2011: x) explains,

'One could say that the original work itself is a translation. The socio-economic circumstances peculiar to the western parts of central Kerala, the large scale cultivation of cash crops, and frequent interaction with Christian and Muslim traders led to a situation where the Araya tribe imbibed the dialect common to that region, thus bringing about the erosion of a wholly tribal language.'

When a subaltern embarks into a literal language or uses a part of it for expressing herself, overtakes her own linguistic texture, thus overlaps all stretches of identities on the basis of space and time, transpose the self and the distinctive representation. Spivak clarified that when the subaltern starts to speak out, she will not be the same. Genuinely she will mix up with the language of authority against she had stood, which would fully or partly be

\footnotetext{
${ }^{3}$ Conceptually this is against the Poly system theory in translation deliberated by Itamar Even Zohar, which refers to a positive influence on a weaker language while translating.

${ }^{4}$ Spivak's essay 'Can the subaltern speak' argued that the subaltern cannot speak in the language of the elite. In latter discussion she explained that when a subaltern starts to speak, she no longer belongs to that representation.
} 
shaded on her version. When writing itself is bounded to transposition and transformation, translation cannot make it unbinding. For justification she can only say 'I have adhered to Narayan's technique of including a few community specific words to give the reader a feel of the original' (2011: $x$ ). But later the translator has added that she tried to avoid a literal, verbatim translation.

'The language is stark, to the point of being bald. The narrative often has a telegram-like abruptness where several words are left unsaid and intelligibility is taken for granted. At times, the author gives no clue as to the identity of the speaker, while this style of writing does not pose a problem to the native reader, it would be utterly bewildering to the target audience. Therefore, it became necessary to insert connectives wherever the style compromised reception. Of course such interpolations have been included only where they are absolutely necessary'(2011: xi).

In case of these types of English translations, interpolations make the translated text more acceptable to the target readers, which is said to be the main contributing component of the success of translations. Appropriations made for readability and additions and deletions to cope with market pressures are also seen. They enlarge the visibility of the textual content, not the coherent life of the underprivileged. Nevertheless translation is not called as a selfless act, rather political activity, a bold act of revolt. The aim and objective of this revolt derails within the act and not addressed even after. Survival instinct stressed in the tone of the earlier renderings is being negotiated in this process of attaining more space and visibility and it becomes an integral tactic of these rewritings. Mirror images produced and circulated in the name of Dalit expressions have contributed to harm to the indigenous in terms of their unique features and organic structures. Leading linguistic terms do not fulfill the gap. It is noted that the target expressions absorb the whole unknown shades of resources and make them understandable. Alarming that, during the changing times, 'Dalit' became a demeaning word for many.

\section{Political Correctness in Translation}

Since there is no universal strategy accepted for text translations, each case has to be kept under scanner in their respective peculiarities and pluralities. Here in the case, the concerns forwarded by the translator are related to the remote tribal surroundings. The inclusion/exclusion of community specific terms determined more or less by the following concerns: their ability to project the tribal ethos, kinship ties, lifestyle etc; an absence of appropriate equivalents in the target language; and to convey a feel of the original. During the process of rewriting, literary compartmentalization leads to a hypertext formation which is prevalently seen in these texts. Dalits claim that their literary pieces should be projected as their place of protest, not a place to 
follow canonical poetics practiced by parochial literary establishments and they often try to transpose them for their political correctness.

Retaining the relative formations of clan-based kinship in the target text or searching equally valued expressions for region specific herbs and plants are futile since usually there is no reference available on them anywhere in the target context. The refusal of traditional aesthetic ghetto is acceptable for the special advocacy of reproduction where as the majority status of English is determined on the basis of politics, economic and cultural adaptability engaged in the process. These components do not match in the case of any tribal language. Thus translations from or into English always have paradoxical relationships with these components.

Minority languages, or minority life expressed in literary language have fundamentally paradoxical while putting them in English. To avoid a battle with the author, these translators adopt an agreement with the author first before publication. Either she includes the author's version of consent or makes a statement that 'titles introduced and included for chapters after discussion, which is approved by the author'. Actual state of translation in this context is made or being arranged not on the basis of cultural or linguistic reasons, but appropriated on a view to economic, political and market gains. Widely used illustrations in English version prove this.

\section{Linguistic Hegemony}

In action, English plays as the language of the oppressor. In case of Indian languages, the majority matter goes imminent but the hegemony of English over regional languages is relatively different, but stark in manner. So identity of a particular community through a language makes its transformation visible in English which retrieves an academic problem, though it is an essential and accepted way of propagation of texts in a multilingual society. Parallel statements possible in languages, but not been accepted blindly in a relationship with a language of hegemony. It is questionable that why the so called advanced man, his society and superior language need to understand an Adivasi's life or her worldview, unless he is interested in that topic/research. They found to be broken, distributed and dismantled in terms with the system of standards practiced and accepted by the larger linguistic world.

'Dalit' the notation itself is heterogeneous. Caste and its plural but brutal experiences thrashed by the notation of Dalit, in textual use. Thus it is a potentially problematic issue to be represented in every act of discourse. So 'Dalit' word is challenged by organizations and government of Kerala has recently issued an official order against it, also realized by social media. But the matter could not make any impact in academic realm, because of its created and reserved practices. Castes, sub castes are not mentioned or expressed in the word Dalit, while its realities and concerns are combating together with every aspect of social and administrative forums. In India, the word Dalit posits the meaning of subaltern and includes all representatives 
from the side in its preview. Writer, Narayan objects this idea and shares his anxiety on a political unity between Adivasi and Dalits-

"I do not care about being politically correct, I'll say this openly; the difference between the two-the Dalit who was subjugated and degraded within the caste system and the tribal who lived a difficult life but retained a definite identity- is as glaring as day and night. Then where is the meeting ground between the two? How can you expect the former to protect the rights of the latter?"(2011:213). ${ }^{5}$

Probably this stand has paved way to non-inclusion of Narayan in the much awaited and acclaimed collection of 'No alphabet in sight'. Similarly, Lakshmi CS (Ambai)'s remarks about English Translations from Indian Languages has a point to see,

'I have come to realize that there is a politics to translation, with a constant undercurrent of a notion of power in the act of translation into English. It involves the choice of text, translation and rendering, and the presentation of the author'. 6

Inherent violence involved in the activity of translation narrated also by earlier theoreticians. ${ }^{7}$

The Tribes have an intimate association with their land preferably say forest, and herbs. Each group has its own curative methods and medication, diverse cropping, hunting, fishing styles inherited through ages. C. K. Janu's views on fractured relationship with the land changed through the times support this. When she acquires land, her life circumstances change a lot. In the context of Kerala, It is assessed that large scale of felling of trees of rubber and tea plantations in Idukki, tourism guided encroaches in Munnar and deforestation in Wayanad have changed the worldview of Adivasi and their patterns of communication are damaged, mixed and collaged subsequently. Their communication methods changed in its pace and shifted to practically usable form of mixed language. No Adivasi expression sustains now, its earlier internal system collapsed or structural sense defused. Then, erosion of tribal languages/meanings/usages/ ethnolects/dialects/idiolects has

\footnotetext{
${ }^{5}$ Interview with the author (Narayan) by the translator (Catherine Thankamma).

${ }^{6}$ C. S. Lakshmi has an opinion that not only the English Translators, but also readers of English are highly benefitted, privileged, helped and powered in their acts of reading. 'English readers, I realized, can never be troubled to understand the translation. They are privileged readers and so everything including food, clothing and relationships, must be explained to them with footnotes, end-notes and glossaries'. She is in the opinion that 'I believe that stories are not about revealing; they are about hiding.' (Lakshmi:3)

${ }^{7}$ Mona baker explained this in her introduction to the article. 'Translation is inherently violent because it necessarily involves reconstituting the foreign text in accordance with values, beliefs and representations that pre-exist it in the target language, The translator exercises a choice conceiving the degree and direction of the violence at work in his or her practice' (Baker: 65).
} 
become a well discussed academic problem. Along with this, words related to different memories and peculiar rituals got fractured and transposed. For example, appeasing god with drink, offerings to tree and animals, different methods of harmony with the surrounded landscape are rituals either changed or appropriated. Their life patterns replaced owing change of time and space. They served creative and specific sense to distinguish the identity of every tribe, which is slowly converged into a single platform called Dalit in writing and rewriting. Representation has got channelized and integration of communities envisioned, but not happened, and this created a distorted value system and cultural confusions in each. Accepted that control over land and tongues are essential for political suzerainty. So the community chronicle is a matter of discussion in the preview of administrative sanctions, which should be added in academic discourses of Dalit writing and rewriting. Strategies adapted to balance loss and gain or optional substitution must be deliberated here. The spirit of the original in a literal language itself is a point here, which raises problems in linking of expressions and stipulates connotative meanings. There is no comprehensive or cohesive method adapted to tackle this problem. Community based word formations and their indefinite traditions and inheritance are not officially imbibed and approved even in standard or literal language, which are said to be successfully translated, universally accepted and stipulated.

\section{Dissemination or Dismantling Knowledge}

Conversion of a language into another can be an adjustment and procedural way of time, not an ultimate method for the approximation or transformation even it is based on positive creativity. It is a technique, driven and recommended by the target group, sometimes claimed by a writer or a translator. While Synchronizes to an elite language and its interests, broken knowledge disseminates, sometimes, without the knowledge of the writer or translator. Documentary nature of language leads to textual constraints, whereas instrumental nature can be well used to create alternatives or possibilities. Internalization through adjustments and agreements in version causes mental block to the delineated or deprived. Marketing technique used for English Translations like 'No alphabets in sight' reckons this. ${ }^{8}$

And if knowledge is of and for everyone, no doubt that Dalit writing and its epistemological content should be utilized, propagated and communicated to all. Being impetus in that domain, it undergoes approximation while in writing since it is not formatted in the literal. In a strong urban cultural background and thus developed academic jargons and discourses can easily create hurdles before them. Consolidation practices are going on, but

\footnotetext{
${ }^{8}$ In the same book, Writer C. Ayyappan forwarded his view on how and when he was called a dalit writer. 'It is not that I read Ambedkar and then started writing, I wrote from my background and out of my experience, after the emergence of a Dalit consciousness, some people began to refer to my stories as dalit'(Tharu, 2011: 349).
} 
enduring, surviving and persisting of Dalit epistemology is still a problem. Some may say, procedural glance of a translator, rather than the practiced gaze of an academic could be rise up occasionally to serve the purpose.

Meanwhile creolized mixtures used a lot in these categories of writings and rewritings were well accepted and acclaimed after the publication of Arundhathi Roy's The God of Small Things. Homogeneity inducted in English translations questioned by theoreticians, and they explicitly stated that ethnic Indian linguistic patterns are more easier to translate in regional languages, in comparison to English, as stated by Meenakshi Mukherjee (2008: 65) reiterated latter by activists and writers. Making voices against caste and race through English, a language of hegemony is propounding in the whole act of writing. Diverse tongues of Dalits replaced in English never been a representative of all narratives, with different identities. Also imminent to see whether the translated language subverts the knowledge of the source with its procured accents, vocabulary, synthesis, diction and identification.

Kancha Iliah like Scholar argues that English helps to redefine the Dalit. Adding to this Context, Rita Kotari's (2013) argument is that

'Dalits in India speak different languages, and so asserting one language (means English) would yield neither a territory nor a representation of all forms of Dalit identities. English helps redefine identity and imagine a pan-India Dalit unity, while also allowing a vocabulary of Human rights.' 9

The question is what type of redefinition happens and who is benefitted from that formation. Learning and practicing English is essential in certain contexts, whereas it is no medicine while tackling with pluralistic practices. Contrary to the earlier opinion, it can be eradicative to the whole beauty of heterogeneity. The possible and contextual ways to keep sensibilities of Dalit without harming their mobility and sustainability must be addressed. Pan Indian Dalit identity serves to cover their tribal, linguistic and ethnic diversities, which are essential to keep their 'self' and individual identification. Even though, Dalit can be a comfortable notation in discussion, a representation above casts and their linear differences should be noted. Dalit as a person or community member contest with his citizenship here, and his representational image is advocated by his social or national status. This shift becomes inevitable in the context of English translations.

Doctor is Fake is a well-known short story written by Kerala's AdivasiTribal writer Narayan. In this story, a fake doctor deceives and mocks an indigenous Adivasi old man on his Ottamuuli (Panacea) and treats people.

\footnotetext{
${ }^{9}$ Though English can be said to be a casteless language in its grammatical ground, no doubt that it is the language of hegemony and power, deeply expressed in its usage, tone and style. Its impact on Indian cultural space is held to be above all discrimination of caste. Above all, racial issues depicted and narrated in English expressions are more vulnerable(Kothari: 67).
} 
Necessarily he losses vision, wisdom and discipline which are implicit in that treatment, fails to cure, though this practice seems to be a mimic of the old man. Likewise, mimesis, developed through marketing techniques adopted and applied to these texts preparations rarely combat with the preservation of their aim or tradition of knowledge systems in larger perspective.

Equality is not anywhere. Sometimes it is not necessary altogether. Equal expression in target language is an old concept in the case of class, rank and level bound translations, where the act becomes a method which cleverly indicts the minor status to the earlier version and to subvert the collective knowledge/s defused in its memory, subjectivity and historicity. English has its hegemonic vocabulary and prevalent standard terms, though translators try to elaborate the discursiveness of these terms while in translation. Transferring of the kinship words, names, customs are normal problems discussed in these type of translations, while the real and vulnerable one is that the textual connotation and its representation of power over the earlier expression drives to present the target text in a different ideology. Widely used and accepted words can even posit derogatory meanings in their tone. For example, when a Dalit uses his caste name in his version, it is explained as a celebration of his identity and where the translator uses, that can be derogatory not only against the first person and also against his community. Recoding the essential identification in favor of the down trodden is a myth, which is always a defensive practice in academic discourse. No doubt, this is rather convenient and safer for the oppressor, not to the oppressed.

\section{Heterogeneity and Translation}

Heterogeneity comprised tribal knowledge and its expression in writing and rewriting, especially into English translations undertakes largely against the distinctive features and otherness in those, always approximates in favor of the target user, which is an accepted and positive practice of the market driven publishing world. Voice of protest translated into standard language usually paves way to a linguistic package known as the version of the subverted or the marginal. People read this as a humanized version, for the sake and satisfaction of both and the wider ethos. The gap between said and its implications permeated in words, mostly inescapably coiling in text translations.

Dalit expressions are not vernacular, but expressive in their ethnic life practices. Like experiences, Dalit expressions less counter the dominant vernacular system. They are transposed to the need of the market, put in the same literal and vernacular modes practiced by those 'whom they counter'. This makes their language and knowledge system demeaning and selfeffacing. Epistemological justice is nowhere in this act. Dalit historians and theoreticians always complaint about this non democratic killing effect of dominant languages. Ethics adopted for the production of knowledge texts and their translation raise questions here. 
Instead of the use of practiced and formally learned alphabets, a counter method can be thought that whether their knowledge can be expressed in any alphabet in use or in any other combined texture form can be experimented in the place of standard words. ${ }^{10}$ Who and how will we make an ethnic language system to be dwelled into an alien but formal language system without hurting mutual intelligibility, without compromising their inherited codes and contexts. No doubt, a translator must be concerned about the priorities and admirations of target readers, which drives his work to be target oriented and naturally he makes options for the majority and accesses helpful ingredients. Here, the voices of grievance and protest inflicted in the confluent tribal systems contrast with the elitist, open and populist choices made in rewritings.

In general, linguistic transfer for wider audience is a matter of happiness and hope for any writer. It can give popularity and wider appreciation. But positive neutralization of texts widely practiced, which is necessary in these rewritings. Among which influence of canonical structure found in the third world translations is one point agreed by many theoreticians. Kinship, custom related expressions are normally discussed as untranslatable or problematic in the process of transposition. But those are outer layered problems whereas tone of speech, flavor of content and style of these narratives are continuously negotiated in their respective literal language followed in translation in English. The strategy opted is using clan when and where possible. Counter argument is that these structures need not be reinforced since they are hardly considered to make any change in the target world because they are not related to its cultural domain.

\section{Problematic Visibility}

Market success or wider publicity can make an impact on the author/translator, always not necessarily positive. Writer Narayan expressed unhappiness over 'benefits' by his translations. According to him, he is famous in many ways, but struggling for survival as a being and a writer. He would like see his community knowledge survives and benefited by his writings, but feels to fail in all ways. The concept of wider visibility becomes problematic here, contrasts with the ethnic survival of the writer or his community. Normally, writers and translators asked to transfer Dalit knowledge into English for the manifestation of otherness and to establish inclusiveness. Their quest for communal identity collides with the concept of

\footnotetext{
${ }^{10}$ The known discussion in current Malayalam situation is one related to history of poetry and prose triggered by M. Leelavathi, famous Malayalam orator/writer/critic. The main point raised against her poetic criticism is that she has not discussed on any Avarna/Dalit poetess/poet in her much acclaimed criticism/books. She retaliated that there was none in the history of Malayalam Poetry to be discussed in her particular preview. This gave rise to heated arguments against the exemption of underprivileged in the history of writing of mainstream literature and historiography.
} 
universal brotherhood here. Is it necessary to assimilate and accept Dalit knowledge globally or is it more meaningful to adopt a democratic worldview of any kind of knowledge? Instead of test methods developed to assess translations, as it is a process of replacing or transfer of words or concepts, efforts must be arranged for a conceptual category of inclusion of all type of knowledge systems, which must be evolved and testified within the practices of translation. Attempt to recover, compare and recapture the memory of the Dalits is said to be one of the method which will help to ascertain themselves by reregistering their history and life in their own view.

Dalit knowledge is an idea related to ethnic concern and elusive terrain, since their knowledge is never accepted and understood as one. Their epistemology is about distribution, not accumulation. Rather their occasional usage pulled out only as a part of postmodern academics or critiques because of this separate background. The challenge is to incorporate multiple intrinsic attributes with in a language system and its translation. Knowledge with no alphabet made into textures of time and oral tradition into script bound publication always suffer setback or disability while register into a standard one. Thus concept of Dalit knowledge and epistemology undermine the concept of replacement in a standard, rational, structured and elite language system, which said to be not efficient enough to carry organic flavors of 'disbeliefs and out beliefs'.

\section{Conclusion}

English possesses powerful linguistic and hegemonic order, which provides the translator a Gregory Rabassa syndrome, ${ }^{11}$ which can be assessed in the pattern and presentation of such translations. The simple point that raised by this side is that their memory cannot be reproduced in the current pattern of any language, and any current language cannot posit their memory. Thus the process of writing itself counters within, adding an inescapable problem to the post writing. In Indian set up, English learned person usually avails a superior status over a regional language speaking person on her/his broadened communication possibilities. Likewise Indian regional language writings are largely affected and undervalued by the command of English. As an assertive language and an effective tool for attaining market benefits, more than the content and its ethnic priorities, the medium allows it to be more influential and claims as an international reproduction. Linguistic patterns which have the ability of an aesthetic break to transcend tribal epistemology in the form of written or rewritten language must be tried, which will prevent all involved from fantasizing about the otherness of the other and also not at the risk of fetishising anyone.

\footnotetext{
${ }^{11}$ Gregory Rabassa is the translator of Gabriel Garcia Marques's world famous novel, One Hundred Years of Solitude. Marquez has generously accepted that Rabassa's version of the novel is far better than his. Author Marques has been elevated to the whole world by and through this translation and eventually won the Nobel.
} 
Translation, Nation and Knowledge Society

\section{References}

BAKER, MONA. (ed.). 2010. Critical Readings in Translation Studies., London: Routledge.

BAMA. 2000. Karukku., Trans by L Holmstrom. Chennai: Macmillan.

BHABHA, HOMI K.1994. The Location of Culture., London: Routledge.

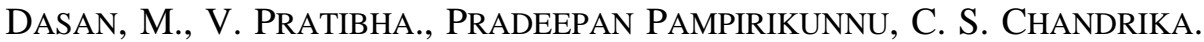
(eds.). 2011. The Oxford India Anthology of Malayalam Dalit Writing., New Delhi: OUP.

Foucault, Michel. 1998. The History of Sexuality I: The Will to Knowledge., London: Penguin.

JAMEELA, NALINI. 2005/2007. The Autobiography of a Sex Worker., Trans by J Devika.Westland Book private Limited.

BHASKARAN. 2004. Mother Forest The Unfinished Story of C. K. Janu., Trans by N. Ravishankar. New Delhi: Kali for Women.

IllaiH, KANCHA. 2000/1996. Why I am not a Hindu?. Calcutta: Samya.

KothARI, RitA. 2013. Caste in a Casteless Language? English as a Language of 'Dalit' Expression. Economic \& Political Weekly 48(39).

LAKSHMI, C. S. 2014. Ways of seeing., A Feature on C. S. Lakshmi., The Hindu.

Limbale, S. 2003. The Outcaste. Trans by S. Bhoomkar. New Delhi: OUP.

MAYILAMMA. 2006. Oru Jeevitam. Transcribed by Jyothibai pariyatath. Kozhikkod: Mathrubhumi.

MARqueZ, Gabriel Garcia. 2007. One Hundred Years of Solitude. Trans by Gregory Rabassa. New Delhi: Penguin India.

MORRIS, C. ROSALIND. (ed.) 2010. Can the sablatern Speak?Reflections on the History of an Idea. New Delhi: Columbia University Press.

MukHERJEe, AloK AND ARUn P. MukHERJEe. In CONVERSATION WITH SHARANKUMAR LIMBALE. Online: https://dalitliterature.wordpress.com/ event-4/.

MuKHERJEE, MEENAKSHI. 2008. Elusive Terrain, Culture and Literary Memory. NewDelhi: Oxford University Press.

NARAYAN. 2011. Kocharethi. Trans by Catherine Thankamma.New Delhi: Oxford University Press.

NARAYAN. 2011. Kathakal.Kottayam: Sahitya Pravarthaka Sahakarana Sangham.

PAWAR, URmila. 2009. The Weave of My life A Dalit Woman's Memoirs. Trans by Maya Pandit. New York: Columbia University Press.

PAITHLEN, SREEJITH. 2010. Ente Jeevitham. Kottayam: DC Books. 
PraKKanam, SeleENA. 2013. Chengara Samaravum Ente Jeevithavum., Kottayam: DC books.

RoY, ARUnDHATHI.1997/2017. The God of Small Things. New Delhi: Penguin Random House.

STEINER, George.1975. After Babel. London: Oxford University Press.

Tharu, Susie, K Satyanarayana. (eds.) 2011. No Alphabet in Sight: New Dalit Writing From South India Dossier 1: Tamil And Malayalam. New Delhi: Penguin Books India.

VALMIKI, OMPRAKASH. 2003. Joothan: A Dalit's Life. Trans by Arun Prabha Mukherjee. Kolkata: Samya. 